\title{
Identifying and Selecting Key Sustainable Parameters for the Monitoring of e-Powered Micro Personal Mobility Vehicles. Evidence from Italy
}

\author{
Elena Carrara, Rebecca Ciavarella, Stefania Boglietti, Martina Carra, Giulio Maternini and Benedetto Barabino \\ Department of Civil, Environment, Land and Architecture Engineering and Mathematics (DICATAM), \\ University of Brescia, Via Branze 43, 25123 Brescia, Italy; e.carrara001@studenti.unibs.it (E.C.); \\ r.ciavarella@studenti.unibs.it (R.C.); s.boglietti001@unibs.it (S.B.); martina.carra@unibs.it (M.C.); \\ giulio.maternini@unibs.it (G.M.) \\ * Correspondence: benedetto.barabino@unibs.it
}

Citation: Carrara, E.; Ciavarella, R.; Boglietti, S.; Carra, M.; Maternini, G.; Barabino, B. Identifying and Selecting Key Sustainable Parameters for the Monitoring of e-Powered Micro Personal Mobility Vehicles. Evidence from Italy. Sustainability 2021, 13, 9226. https://doi.org/10.3390/su13169226

Academic Editor: Miguel Amado

Received: 5 August 2021

Accepted: 15 August 2021

Published: 17 August 2021

Publisher's Note: MDPI stays neutral with regard to jurisdictional claims in published maps and institutional affiliations.

Copyright: (c) 2021 by the authors. Licensee MDPI, Basel, Switzerland. This article is an open access article distributed under the terms and conditions of the Creative Commons Attribution (CC BY) license (https:// creativecommons.org/licenses/by/ $4.0 /)$.

\begin{abstract}
The recent invasion of electric-powered personal mobility vehicles (e-PMVs) in many cities worldwide has disputed the transport sector and captured the attention of academics, practitioners, and public administrators. Indeed, these vehicles are believed to be sustainable transport alternatives. Therefore, understanding how to evaluate and monitor the related performance is crucial and may be addressed by suitable key sustainable parameters (KSPs) to inform on the excellences and criticalities of e-PMVs. Previous research has focused largely on "how to measure and manage" KSPs rather than "what to measure". Conversely, as far as the authors know, no study investigated objective methods for identifying and selecting top KSPs. This paper covers this gap by proposing a cohesive approach, which identifies a long list of KSPs, defines their properties, involves experts to elicit judgments for each KSP, evaluates the long list, and returns the most promising set. This approach is demonstrated with an application based on an Italian survey. A circumscribed and relevant set of six overlapping KSPs is derived by merging two different approaches. These results may support the opportunity to assess the performance of e-PMVs among cities according to a common set of KSPs.
\end{abstract}

Keywords: micromobility; personal mobility vehicle; sustainability assessment; analytic hierarchy process; sustainable micromobility parameters

\section{Introduction}

Nowadays, sustainability has become one of the core objectives of the transport sector worldwide. The rapid growth in energy consumption, environmental pollution, and climate change is receiving increasing attention. These facts captured the attention of academics, practitioners, and public administrators to reinvent transport modes towards less energy-intensive solutions such as electric micromobility devices to achieve a more sustainable urban transport [1,2]. Generally speaking, electric micromobility refers to electric-powered micro personal mobility vehicles (e-PMVs) and aims to serve the mobility demand for short and medium-range trips (within $5 \mathrm{~km}$ ). The e-PMVs include microvehicles that can be driven while seated (i.e., electric scooters, pedal-assisted or electric bicycles) or standing (i.e., e-kick scooters, segways, hoverboards, and monowheels).

Nowadays, e-PMVs (privately or shared) are mostly invading large urban contexts (e.g., Rome, Milan, Paris). They are believed to be an environmentally friendly new transport mode because they may increase community relationships, reduce emission levels, and improve air quality. In addition, e-PMVs could reduce traffic congestion-and consequently, travel times-due to the possibility of using a viable transport alternative in urban areas for many users. However, some studies showed that they could replace walking and cycling without reducing the use of private cars for short trips, e.g., [3]. Therefore, the praised sustainable benefits of this new transport mode could be wholly or partially disregarded [4-7]. 
Owing to this exceptional spread, the interest of academics, practitioners, and public administrators towards e-PMVs has grown considerably and caused several challenges, such as monitoring the performances of e-PMVs. For instance, many public administrators could be unprepared to monitor the performance of e-PMVs in their contexts (e.g., where to locate the charging infrastructures, the numbers of riders) without a clear and effective set of parameters representing their characteristics. Thus, these parameters are a fundamental input in monitoring e-PMVs because they help detect excellences and criticalities. Therefore, the selection of key sustainable parameters (KSPs) is crucial for this task.

However, little attention has been paid to the following three issues.

First, relevant inclusive reviews investigated many issues of e-PMVs, seeing as how they are a quite recent and hot research topic. O'Hern \& Estgfaeller [8] provided a scientometric review to synthesise, sort rapidly, analyse bibliographic data, and display the evolution of mobility research in the field of micromobility in terms of time, region, and numbers of citations. Boglietti et al. [9] reviewed endogenous and exogenous issues of e-PMVs. The former refers to problems strictly related to the use of e-PMVs in public spaces, while the latter refers to the external effects of their use, therefore, their impact on users' road safety and the environment. Lastly, Sengül and Mostofi [10] reviewed the impacts of e-PMVs according to travel behaviours, energy consumption, environmental impacts, safety, and related regulations. Surprisingly, despite these quite comprehensive reviews, there is a lack of research focused on identifying parameters (or indicators) suitable to evaluate and monitor e-PMV performance over time. Boglietti et al. [9] also noted this research gap and stressed the importance of monitoring e-PMVs with proper parameters.

Second, existing research is focused on the development of models and methods on how to measure and manage KSPs rather than on what to measure [8-10]. Indeed, previous research rarely investigated parameter selection mechanisms by objective methods.

Third, according to Castillo and Pitfiled [11] and Barabino et al. [12], selecting suitable KSPs presents some challenges, which require a systematic method to improve their acceptability and credibility among experts. Although many potential KSPs may be considered, the selection of a compact subset of them may be tricky. Moreover, since KSPs are only constructs of the e-PMV system, it is challenging to select those more suitable for its characterisation.

Considering the previous drawbacks and challenges, this study proposes a cohesive approach to identify and select a pool of KSPs able to provide a high-level direction for monitoring the performance of e-PMVs. At first, this approach identifies a long list of KSPs; next, it points out components and attributes for KSPs and involves experts to obtain judgments on each KSP. Finally, it evaluates and ranks KSPs by a weighted outcome score. These evaluations are carried out on the data collected by Italian experts involving academics, practitioners, and users of e-PMVs. This approach differs from ELASTIC, i.e., a framework for identifying and selecting sustainable transport indicators by UK experts [11]. Moreover, it differs from other research, which proposed an integrated approach to select a set of key performance indicators to monitor the transit service quality [12].

Since a key goal of each form of sustainable transport (including e-PMVs) is the evaluation of its performances, the content of this study contributes to the progress of analyses and monitoring on the use of e-PMVs for academics, practitioners, and public administrators. Indeed, this study sheds new light on a research area that has been largely neglected. For instance, academics and practitioners could re-think the need to accommodate e-PMVs in urban spaces, and public administrators could measure KSPs to evaluate their benefits and downfalls.

The remainder of the paper is structured as follows: Section 2 reviews the related and relevant literature. Section 3 describes the cohesive method characterised by six procedural steps to identify and select the most suitable KSPs describing the performance of e-PMVs. Section 4 presents the results of the most promising set of KSPs. Section 5 discusses the results in the context of the literature. Finally, Section 6 concludes the study and provides research perspectives. 


\section{State of the Art KSPs}

The search of parameters in the literature was carried out through the Google Scholar and Scopus databases. These databases identified articles from the academic literature using multiple keywords (i.e., e-scooters, micromobility, sustainable micromobility, sustainable transport, environmental sustainability, electric vehicles, sustainable transport indicators). The reading of titles and abstracts enabled a more accurate selection of sources consistent with the topic studied. Given the number of identified parameters, we categorised them into key criteria, representing a reference theme. Each key criterion has an associated parameter category that can be further divided into sub-parameters and sub-sub-parameters (if any).

More precisely, Table 1 lists the recent literature and provides a summary of parameters for the possible evaluation of the performance of e-PMVs. Table 1 is organised into four parts. The first part contains sources, and the second specifies the number of key criteria (\#KC), parameters (\#P), and sub-parameters (\#sP) for each source. The third part specifies which key criteria and parameters were investigated, and, finally, the fourth part shows how these parameters were selected from the literature. In addition, Table 1 is alphabetically ordered according to the source.

Data reported in Table 1 leads us to two considerations.

As for the first consideration, the key criteria concerned economic, environmental, safety, social, and urban and transport planning issues.

The economic criterion included the costs of users to use the service. Therefore, the cost reduction and increased performance of e-PMVs in terms of effectiveness and sustainability were considered. The economic criterion referred to the travel costs incurred by users and the time spent travelling due to traffic congestion. Indeed, market analyses showed that the costs of managing, maintaining, and operating e-PMVs were significantly lower than the vehicle itself. Furthermore, given the possibility of travelling on a priority lane, the use of e-PMVs reduced travel time compared to other means of transport $[13,14]$.

The environmental criterion included several parameters to monitor the impact that e-PMVs had on the surrounding environment: energy savings, $\mathrm{CO}_{2}$ emissions, and other emissions. The release of $\mathrm{CO} 2$ is influenced by the materials utilised and the production processes, including the related charging stations. Emissions could depend on several facets, including the vehicle's LCA emissions, type of fuel used, mode of transport replaced, and their daily management. Finally, parameters such as the battery capacity, alternative transport choice, consumption of energy use, or renewable energies could affect the energy saving of e-PMVs [5,15].

Being a transport mode, many authors highlighted the safety criterion in e-PMV systems. They considered, on a case-by-case basis, the internal and external users of the system. The parameters evaluated the number of crashes and types of injury associated with the crash. Consequently, other parameters focused on the optional devices available (for the vehicles or users) to prevent crashes or limit their injuries, or again the user's knowledge of the traffic rules and the different types of speeds allowed, including the speed limit of the vehicle itself. Finally, some studies focused on the perception of safety both by pedestrians and by the user of the e-PMV [16-18].

The social criterion referred to studies examining the impact of e-PMVs on people's lives and population characteristics, both in terms of user habits and fairness of the service to the population. Parameters were based on social and economic equity (i.e., gender, race, employment, education, income), the number of trips, kilometres travelled, travel time, and the average age of users. $[19,20]$.

Finally, the urban and transport planning criterion considered the sustainability of e-PMVs within the definition of urban development and sustainable transport systems that involve the well-being of people and the design of the urban environment. Specifically, it included evaluating infrastructural parameters such as the presence or absence of routes dedicated to e-PMVs, recharging stations, rentals, or conflicts with the road or parking areas. Some parameters concerned the impacts on mobility systems depending on the use 
of urban space and a multimodality offer. Moreover, an analysis of the possible demand for e-PMVs grouped the population density, connection, and distance from the attractors of the city (e.g., city centre, shopping centres, schools, offices, parking lots) [21-23].

The second consideration concerned the selection of the parameters. It was carried out by three different approaches. The selection of parameters from previous literature (L) on e-PMVs is the prevalent type. By this approach, parameters were selected by drawing on previous relevant studies about e-PMVs. They ranged from road safety to the perception of users and non-users $[18,21,24]$. The second approach selected the parameters through specific corporate inquiries $(\mathrm{C})$. Therefore, parameters were selected according to the goals or objectives of the organisations. The commonality between studies is the willingness to guide mobility strategies. For example, Schellong et al. [25] analysed the market of the main companies due to highlighted opportunities for mobility service providers and platforms. Clewlow [17] examined the potential of e-PMVs in several USA cities through a database of private companies. In both approaches, no report or study presented a ranking of the best parameters for evaluating e-PMVs. Conversely, the third approach is based on models and/or methods (M). More precisely, some studies applied simple regression [26] or spatial regression models $[19,23,27]$ to existing e-PMV systems (e.g., Austin, Louisville, Minneapolis) to explore which parameters affect e-PMV travel or usage patterns. The regression highlighted the significant parameters related to, e.g., demographics, density, social or economic diversity, land use, design, distance to transit, and other transportrelated variables that affect e-PMV travel or usage patterns. Caspi et al. [27] deduced that the level of employment and charging infrastructure influences the use of e-PMVs. Hosseinzadeh et al. [23] and Bai \& Jiao [19] showed the relevance of proximity to certain attractive areas such as shopping centres or city centres.

From the previous literature, it appears that the study by Møller et al. [28] considered more sub-parameters, followed by Bai \& Jiao [19] and Gossling [18] with 14, 13, and 11 subparameters, respectively. However, the categories developed did not fully include the identified criteria (e.g., territorial planning, security, economic, social, and environmental). Bai \& Jiao [19] focused mainly on the social and urban planning and transport aspects. In contrast, Gossling [18] debated safety, and Møller et al. [28] used the environmental and economic facets. Gitelman et al. [26] considered four of the five key criteria identified and only left out the social aspects. Overall, the literature analysis showed particular attention to KSPs related to the aspects of urban planning and transport (42), environmental (41), safety (31), social (21), and economic (10).

Nevertheless, despite this high-quality literature, no study proposed a cohesive method to identify and select the most promising set of KSPs. This study covers this gap. 
Table 1. Summary of potential parameters for the evaluation of the performance of e-PMVs.

\begin{tabular}{|c|c|c|c|c|c|c|c|c|c|c|c|c|c|c|c|c|c|c|}
\hline \multirow{2}{*}{ Source } & \multirow{2}{*}{ \#KC } & \multirow{2}{*}{$\# \mathbf{P}$} & \multirow{2}{*}{ \#sP } & \multicolumn{4}{|c|}{ Economic Environmental } & \multicolumn{4}{|c|}{ Safety } & \multicolumn{2}{|c|}{ Social } & \multicolumn{4}{|c|}{ Urban and Transport Planning } & \multirow[t]{2}{*}{$\begin{array}{c}\text { Parameter } \\
\text { Selection }\end{array}$} \\
\hline & & & & UC & CR & ES & OE & $\mathrm{C}$ & PS & VF & TR & $\mathrm{CP}$ & IPL & $\mathbf{I}$ & TI & $\mathrm{AT}$ & UCF & \\
\hline Abduljabbar et al., 2021 [13] & 4 & 5 & 5 & - & $\bullet$ & & $\bullet$ & & & & & $\bullet$ & & & $\bullet$ & & & $\mathrm{L}$ \\
\hline Alessio, 2019 [29] & 3 & 4 & 4 & $\bullet$ & $\bullet$ & & $\bullet$ & $\bullet$ & & & & & & & & & & $\mathrm{L}$ \\
\hline Badeau et al., 2019 [16] & 1 & 1 & 1 & & & & & $\bullet$ & & & & & & & & & & $\mathrm{L}$ \\
\hline Bai \& Jiao, 2020 [19] & 3 & 6 & 13 & & & & & & & & $\bullet$ & $\bullet$ & $\bullet$ & $\bullet$ & & $\bullet$ & $\bullet$ & M \\
\hline Cao et al., 2021 [20] & 3 & 4 & 5 & & & & $\bullet$ & & & & & $\bullet$ & $\bullet$ & & $\bullet$ & & & $\mathrm{L}$ \\
\hline Caspi et al., 2020 [27] & 2 & 3 & 3 & & & & & & & & & $\bullet$ & & $\bullet$ & & $\bullet$ & & $\mathrm{M}$ \\
\hline Christoforou et al., 2021 [30] & 3 & 4 & 6 & $\bullet$ & $\bullet$ & & $\bullet$ & & & & & $\bullet$ & & & & & & $\mathrm{L}$ \\
\hline Clewlow et al., 2018 [17] & 2 & 2 & 2 & & & & & & $\bullet$ & & & & $\bullet$ & & & & & $\mathrm{C}$ \\
\hline Gitelman et al., 2020 [26] & 4 & 4 & 4 & $\bullet$ & & $\bullet$ & & $\bullet$ & & & & & & & $\bullet$ & & & M \\
\hline Gossling, 2020 [18] & 3 & 5 & 11 & & & $\bullet$ & & $\bullet$ & & & $\bullet$ & & & $\bullet$ & & $\bullet$ & & $\mathrm{L}$ \\
\hline Hawa et al., 2021 [31] & 2 & 6 & 6 & & $\bullet$ & & $\bullet$ & & & & & & & $\bullet$ & $\bullet$ & $\bullet$ & $\bullet$ & $\mathrm{L}$ \\
\hline Hollingsworth et al., 2019 [5] & 1 & 2 & 3 & & $\bullet$ & & $\bullet$ & & & & & & & & & & & $\mathrm{C}$ \\
\hline Hosseinzadeh et al., 2021 [23] & 2 & 4 & 8 & & & & & & & & & $\bullet$ & $\bullet$ & & & $\bullet$ & $\bullet$ & M \\
\hline Hwang, 2010 [15] & 1 & 2 & 2 & & $\bullet$ & $\bullet$ & & & & & & & & & & & & $\mathrm{L}$ \\
\hline $\begin{array}{l}\text { International Transport Forum, } \\
2020 \text { [32] }\end{array}$ & 2 & 3 & 4 & & & & $\bullet$ & & & $\bullet$ & $\bullet$ & & & & & & & $\mathrm{L}$ \\
\hline Kopplin et al., 2021 [33] & 3 & 4 & 5 & $\bullet$ & $\bullet$ & & $\bullet$ & & & & & & & & $\bullet$ & & & $\mathrm{L}$ \\
\hline Møller et al., 2020 [28] & 3 & 8 & 14 & $\bullet$ & $\bullet$ & $\bullet$ & $\bullet$ & & & & & & & $\bullet$ & $\bullet$ & $\bullet$ & & $\mathrm{L}$ \\
\hline Nocerino et al., 2016 [34] & 3 & 4 & 1 & $\bullet$ & & $\bullet$ & $\bullet$ & & & & & & & & $\bullet$ & & & $\mathrm{L}$ \\
\hline Piazza et al., 2021 [35] & 3 & 4 & 4 & - & & & $\bullet$ & & & & & & & & & $\bullet$ & $\bullet$ & $\mathrm{M}$ \\
\hline Reck et al., 2021 [22] & 2 & 4 & 7 & & & & & & & & & $\bullet$ & & $\bullet$ & & $\bullet$ & $\bullet$ & $\mathrm{L}$ \\
\hline Scarpinella, 2020 [21] & 1 & 1 & 2 & & & & & & & & & & & $\bullet$ & & & & $\mathrm{L}$ \\
\hline Schellong et al., 2019 [25] & 3 & 4 & 4 & & & & & & $\bullet$ & & $\bullet$ & & & & $\bullet$ & $\bullet$ & & C \\
\hline Siow et al., 2020 [36] & 2 & 3 & 3 & & & & & $\bullet$ & & & $\bullet$ & $\bullet$ & & & & & & $\mathrm{L}$ \\
\hline Smith et al., 2018 [14] & 2 & 2 & 2 & $\bullet$ & & & & & & & & $\bullet$ & & & & & & C \\
\hline
\end{tabular}

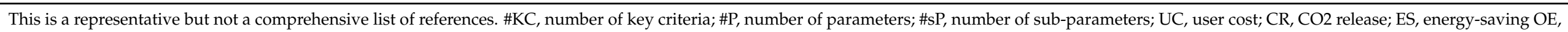

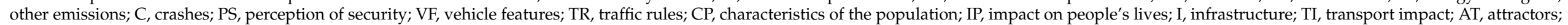

$\mathrm{UF}$, urban centre features; L, literature; $\mathrm{M}$, models and/or methods; $\mathrm{C}$, corporate inquiries. 


\section{Methodology}

The cohesive method for identifying and selecting a set of KSPs is organised into three main phases (and related steps) according to the scheme in Figure 1. Moreover, for the sake of synthesis, criteria, parameters, and sub-parameters will all be referred to as parameters (or KSPs) later. Each phase (and related steps) is described below.

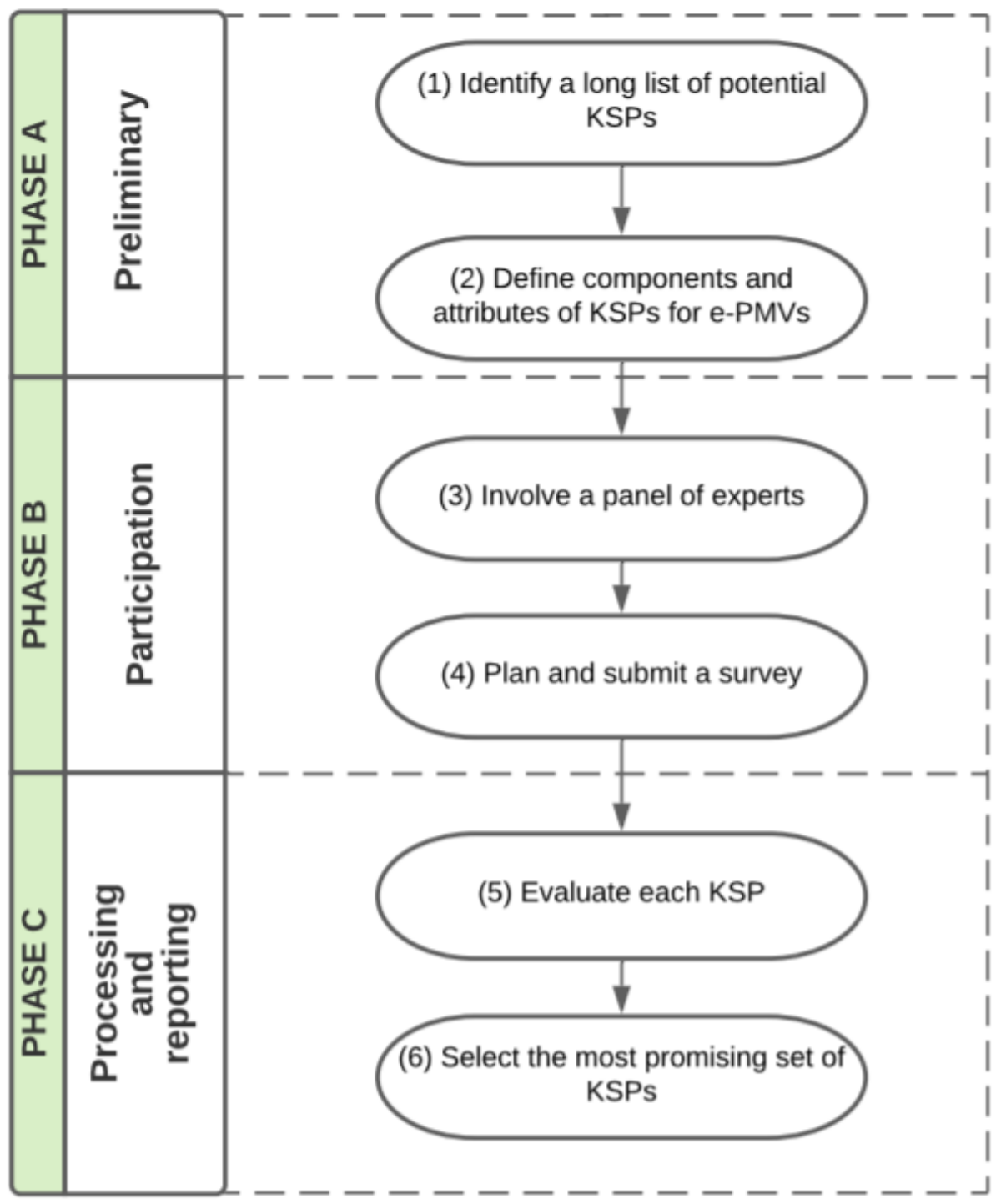

Figure 1. Conceptual model of the method.

\subsection{Preliminary Phase}

Phase A sets some preliminary tasks to frame both KSPs and their related properties. It runs according to steps (1) and (2).

Step (1) aims to collect a long list of the potential KPSs for e-PMVs. Such KSPs can be expanded into more specific sub-parameters to be able to consider each of them separately. In this method, the relevant literature is considered. It identifies the more comprehensive initial source of potential KSPs from scientific databases and reports, as shown in Table 1.

Step (2) aims to define the key properties of KSPs. To perform this task, two manageable components were considered according to [11,12]: (1) the methodological component of KSPs and (2) the sustainability component. The components represent relevant properties of the parameters. However, they could be too broad to cover the selection of KSPs. Therefore, an additional decomposition into more measurable and accurate related at- 
tributes was required. The literature suggested several attributes for the methodological component, and the main ones were taken from [11,12]:

- Measurability: the possibility of evaluating a KSP in a theoretical and reliable way.

- Ease of availability: the opportunity to easily collecting reliable parameter data at a reasonable cost.

- Speed of availability: the option to regularly update the derived or calculated parameter data to minimise the time elapsed between two consecutive measurements.

- Interpretability: the unambiguous output should report parameters that all interested parties easily understand.

Since e-PMVs are believed to be a sustainable mode of transport, the methodological component is accompanied by the sustainability component, according to the concept proposed by the Brundtland Commission [37]. The concept of sustainability is very broad and linked to the compatibility between the development of economic activities and environmental protection. Hence, four attributes for the sustainability component were considered in this study, which also included some of the key criteria that clustered parameters in Table 1, they were:

- Social, a sustainable e-PMV system should contribute to social and spatial equity, meeting the basic mobility and accessibility needs of all social, economic, and geographical groups.

- Environmental, a sustainable e-PMV system should minimise the consumption of natural resources, actively reduce transport-related emissions and waste.

- Economic, a sustainable e-PMV system should contribute to economic growth and support market mechanisms that reflect the true social, economic, and environmental costs of activities.

- Safety, a sustainable e-PMV system should be designed and managed to minimise the risks to health, and the number, severity, and risks of road crashes.

Although all attributes are general, each of them may have a specific level of importance because they vary to reflect different viewpoints.

\subsection{Participation Phase}

Phase B identifies a panel of stakeholders and takes their opinions about components and attributes and their parameters; it runs according to steps (3) and (4). Moreover, for the sake of synthesis, components and attributes will all be referred to as items in what follows, unless they were specified.

Defining the relevance of parameters is not a trivial task; it must consider specific requirements, issues of quality, etc. Therefore, the involvement of experts in the perceived evaluation of parameters is considered a significant phase, which characterises Step (3). Academics, practitioners and aware e-PMV users are here considered "experts". Academics can provide a thorough and suitable evaluation of parameters related to components and attributes at a high level. Practitioners can provide a daily operational judgement from a managerial perspective. Aware e-PMV users can provide an applied evaluation from their viewpoint, which completes the previous theoretical and managerial ones, thus avoiding the common wide gap between users, practitioners, and academics [38]. The involvement of diverse experts is strongly recommended because the different sensitivities, training, and heterogeneous expertise could lead to a different evaluation of components and attributes of each parameter. Since these perceptions can vary due to the specific knowledge on KSPs, and, thus, provide different opinions towards components and attributes, a weighing process is required to derive the relative importance. Hence, weights of importance are attached to components and attributes according to objective methods. Indeed, weights can be directly attached by questioning experts on preferences for a single item. However, this approach might be flawed since humans have difficulties processing relevant information about all items into stable weights, especially when many items are evaluated, e.g., [11,39]. 
Several authors have proposed approaches to weighting items, e.g., [40-42]. In this study, a multi-criteria decision analysis (MCDA) is considered [43-45]. It has the advantage of simultaneously considering multiple aspects (e.g., criteria, goals, actions), both qualitative and quantitative, and enables us to highlight the different perspectives of stakeholders. Using known information (e.g., goals) and judgments expressed in numerical values by the decision-maker, the MCDA determines a compromising solution [46]. The MCDA can be performed by different approaches, each one with different pros and cons. This study chooses the analytic hierarchy process (AHP) due to its positive mitigation of bias risks [47-49]. It helps to model cases of uncertainty and risk because it can derive and combine multidimensional scales-where measures ordinarily do not exist-in a single scale of priority $[50,51]$. Furthermore, it provides a mathematical foundation (e.g., eigenvectors) that establishes weights from each judgment, arriving at objective evaluations.

The AHP consists of a pairwise comparison of items that generates a stable weight assignment. Moreover, in order to reduce possible biases in a decision-making process, the AHP generates a ratio scale for each set of pairwise comparisons to evaluate the consistency/inconsistency of the judgements provided. To do so, the AHP raises subjective comparisons and then aggregates the results into objective weights, solving the issue of subjectivity of the expert involved. Indeed, it resolves conflict or disagreements among groups that may have incompatible goals or positions [52-56]. The application of the AHP itself and all its properties eliminate excessive subjectivity because it translates subjective judgments into objective weights. The AHP results can be useful considering the different facets with multiple measurements that characterise the parameters of e-PMVs.

Expert involvement can consist of various approaches. According to Step (4), a survey is proposed to involve the largest number of interested experts in this study. Among the several survey types available, the choice of a web survey is suggested because of several advantages that make this procedure well-practicable [57]. In detail, the web survey (1) can elicit information at a low cost; (2) rapidly reach experts; (3) be directly compiled online, thus removing the choice to print the questionnaire; and (4) returns data ready to be processed. Moreover, the web surveys are non-intrusive, and the participation is free and without external pressure $[57,58]$. The use of a traditional e-mail survey would be an interesting choice. Indeed, it could be assumed that a file can be saved on a computer or in printed form, and the respondent does not necessarily need to be online to answer. However, the previous advantages suggest adopting a web survey. In addition, during the COVID-19 pandemic, web surveys were one of few applicable tools.

The web survey is organised in two sections and involves the experts twice. The survey has two chosen components (i.e., methodological and sustainability), and experts evaluated which one was more relevant and by how much (e.g., twice as much). Similarly, experts had to indicate an evaluation among the four attributes of each component. Secondly, a matrix containing all parameters and attributes (of both the components) is provided, and experts had to rate each parameter against each attribute.

\subsection{Data Processing and Reporting}

Phase $C$ processes data collected among experts and returns the KPSs ranked with respect to the best values. It runs according to steps (5) and (6) as follows.

Step (5) processes data via two methods. The former includes the application of AHP to translate subjective judgments into objective weights. The second aggregates weights and outcome marks to compute the performance of each KSP.

More precisely, the AHP method consists of mathematical processing, which is organised into several stages. First, a matrix of pairwise comparisons is built for each expert while comparing items. In this matrix, rows and columns report items. Each entry is the weight assigned to an item with respect to one another. Second, starting from this matrix, a vector of weights for each item is first computed and next normalised. Third, since some inconsistency of judgment can be observed, a consistency test is performed to verify the reliability of judgments of each matrix. 
More precisely, let:

- $J$ be the set of experts involved and $j$ an individual expert;

- $\quad P$ be the set of items and $p$ an individual item, i.e., a component or an attribute;

- $\quad w_{\mathrm{p}} / w_{\mathrm{q}}$ be the numerical judgment of the pairwise comparison between item $p \in P$ and $q \in P$, respectively (for instance, $w_{\mathrm{p}} / w_{\mathrm{q}}=2 / 1$ means item $p \in P$ is twice more important than item $q \in P$; thus $\mathrm{w}_{\mathrm{q}} / \mathrm{w}_{\mathrm{p}}=\frac{1}{2}$ means the opposite case);

- $\quad W_{p}$ be the overall unnormalised weight of item $p \in P$, and $w_{p}$ is its normalised value;

- $\quad C I$ be the consistency index, which expresses the consistency/inconsistency of pairwise comparisons. Precisely, the $C I$ measures whether the judgments of the participant are logical and consistent with the choices made throughout the survey;

- $\quad \lambda_{\max }$ be the maximum eigenvalue needed to compute the measure of consistency;

- $\quad$ RI be the random consistency index, a tabulated CI function of the maximum number of items.

The computation of weights and the consistency check of the judgments were performed according to the following four-step algorithm:

For each expert $j \in \mathrm{J}$ :

(1) Build the matrix of pairwise comparisons for each item, as shown in Table 2.

(2) Compute $W_{p}$ and $w_{p}$ from this matrix. More precisely, among the several approaches, the vector of weight $W_{p}$ is computed as follows:

$$
W_{p}=\sqrt[n]{\prod_{q=1}^{n} w_{\mathrm{p}} / w_{\mathrm{q}}} \quad \forall p \in P
$$

Then, $W_{p}$ is normalised through the average arithmetic method as follows:

$$
w_{p}=\frac{W_{p}}{\sum_{p=1}^{n} W_{p}}
$$

(3) Check the consistency.

Table 2. Numerical judgment of the pairwise comparison between items.

\begin{tabular}{ccccccc}
\hline & $\mathbf{1}$ & $\mathbf{2}$ & $\ldots$ & $\mathbf{q}$ & $\ldots$ & $\boldsymbol{n}$ \\
\hline 1 & 1 & $w_{1} / w_{2}$ & $\ldots$ & $w_{1} / w_{\mathrm{q}}$ & $\ldots$ & $w_{1} / w_{\mathrm{n}}$ \\
\hline 2 & $w_{2} / w_{1}$ & 1 & $\ldots$ & $w_{2} / w_{\mathrm{q}}$ & $\ldots$ & $w_{2} / w_{\mathrm{n}}$ \\
\hline$\ldots$ & $\ldots$ & $\ldots$ & $\ldots$ & $\ldots$ & $\ldots$ & $\ldots$ \\
\hline $\mathrm{p}$ & $w_{\mathrm{p}} / w_{1}$ & $w_{\mathrm{p}} / w_{2}$ & $\ldots$ & $w_{\mathrm{p}} / w_{\mathrm{q}}$ & $\ldots$ & $w_{\mathrm{p}} / w_{\mathrm{n}}$ \\
\hline$\ldots$ & $\ldots$ & $\ldots$ & $\ldots$ & $\ldots$ & 1 & $\ldots$ \\
\hline$n$ & $w_{\mathrm{n}} / w_{1}$ & $w_{\mathrm{n}} / w_{2}$ & $\ldots$ & $w_{\mathrm{n}} / w_{\mathrm{q}}$ & $\ldots$ & 1 \\
\hline
\end{tabular}

First, $\lambda_{\max }$ is computed as follows:

$$
\lambda_{\text {max }}=\frac{\sum_{p=1}^{n}\left[\frac{\sum_{q=1}^{n}\left(\frac{w_{p}}{w_{q}} * w_{p}\right)}{w_{p}}\right]}{n}
$$

Second, it should be verified that $\lambda_{\max } \geq n$

Third, $C I$ is calculated as follows:

$$
C I=\frac{\left(\lambda_{\max }-n\right)}{(n-1)}
$$

The evaluations are perfectly consistent if $\lambda_{\max }=n$, thus $C I=0$.

Fourth, the RI is taken from Table 3 according to the number of items considered. 
Table 3. Random Consistency Index.

\begin{tabular}{ccccccccccc}
\hline $\boldsymbol{n}$ & $\mathbf{1}$ & $\mathbf{2}$ & $\mathbf{3}$ & $\mathbf{4}$ & $\mathbf{5}$ & $\mathbf{6}$ & $\mathbf{7}$ & $\mathbf{8}$ & $\mathbf{9}$ & $\mathbf{1 0}$ \\
\hline$R I$ & 0 & 0 & 0.52 & 0.89 & 1.11 & 1.25 & 1.35 & 1.40 & 1.45 & 1.49 \\
\hline
\end{tabular}

Finally, the consistency ratio is computed as follows:

$$
C R=\frac{C I}{R I}
$$

The AHP considers the pairwise comparisons consistent when $C R<0.1(10 \%)$; otherwise, the expert may be re-involved to revise his/her evaluations. More details of the application of AHP are provided in [48-50].

Once AHP returned weights, an aggregate score (denoted by SI) is computed for each parameter. This score is calculated by a simple additive weighting approach that combines the average weight of components and attributes and the outcome marks of each parameter. More precisely, let:

- $\quad I$ be the set of KSPs and $i$ an individual KSP;

- $\quad M$ be the set of attributes of the methodological component and $m$ be an individual attribute;

- $\quad S$ be the set of attributes of the sustainability component and $s$ be an individual attribute;

- $w_{1 j}$ be the weight of the methodological component returned by (2), according to the judgement of expert $j \in \mathrm{J}$;

- $w_{2 j}$ be the weight of the sustainability component returned by (2), according to the judgement of expert $j \in \mathrm{J}$;

- $w_{1 j m}$ be the weight of attribute $m \in M$ returned by (2), according to the evaluation of expert $j \in J$;

- $\quad w_{2 j s}$ be the weight of attribute $s \in S$ returned by (2), according to the evaluation of expert $j \in J$;

- $\bar{G}_{1}$ be the average weight of the methodological component;

- $\bar{G}_{2}$ be the average weight of the sustainability component;

- $\quad \bar{w}_{1 m}$ be the average weight of attribute $m \in \mathrm{M}$;

- $\bar{w}_{2 s}$ be the average weight of attribute $s \in \mathrm{S}$;

- $\bar{V}_{i m}$ be the average mark of parameter $i \in I$ for attribute $m \in M$;

- $\bar{V}_{i s}$ be the average mark of parameter $i \in I$ for attribute $s \in S$;

- $\quad V_{i j m}$ be the mark of parameter $i \in I$ for attribute $m \in M$ according to the evaluation of expert $j \in J$;

- $\quad V_{i j s}$ be the mark of parameter $i \in I$ for attribute $s \in S$ according to the evaluation of expert $j \in J$.

The computation of SI is performed according to the following four steps algorithm. For each parameter $i \in I$ :

(1) Compute $\bar{G}_{1}$ and $\bar{G}_{2}$ as follows:

$$
\begin{aligned}
& \bar{G}_{1}=\frac{\sum_{j=1}^{J} w_{1 j}}{J} \\
& \bar{G}_{2}=\frac{\sum_{j=1}^{J} w_{2 j}}{J}
\end{aligned}
$$

(2) Compute $\bar{w}_{1 m}$ and $\bar{w}_{2 s}$ as follows:

$$
\bar{w}_{1 m}=\frac{\sum_{j=1}^{J} w_{1 j m}}{J} \quad \forall m \in M
$$




$$
\bar{w}_{2 s}=\frac{\sum_{j=1}^{J} w_{2 j s}}{J} \quad \forall s \in S
$$

1. Compute $\overline{V_{i m}}$ and $\overline{V_{i s}}$ as follows:

$$
\begin{array}{cl}
\bar{V}_{i m}=\sum_{j=1}^{J} \frac{V_{i j m}}{J} \quad \forall m \in M \quad \forall i \in I \\
\bar{V}_{i s}=\sum_{j=1}^{J} \frac{V_{i j s}}{J} \quad \forall s \in S \quad \forall i \in I
\end{array}
$$

(4) Compute $S I_{i}$ as follows:

$$
S I_{i}=\bar{G}_{1}\left(\sum_{m \in M} \bar{w}_{1 m} * \bar{V}_{i m}\right)+\bar{G}_{2}\left(\sum_{s \in S} \bar{w}_{2 s} * \bar{V}_{i s}\right) \quad \forall i \in I
$$

According to step (6), KSPs are in decreasing order based on their estimated $\mathrm{SI}_{\mathrm{i}}$. The first top KSPs are selected to be the most appropriate and coherent to measure the performance of e-PMVs.

\section{Results}

\subsection{Preliminary Phase: The Long List of Parameters}

According to Step (1) of phase A, Table 1 summarised the more comprehensive list of parameters to evaluate the performance of e-PMVs. Next, a grouping of similar subparameters was carried out, which were clustered based on the original key criteria. A total of 54 unique sub-parameters was considered, which was not derived from a specific source. More specific characteristics of sub-parameters have been inserted in the latest column of sub-sub-parameters reported in Appendix A. Next, components and attributes pointed out in Step (2) represented a data input in the selection process.

\subsection{Participation Phase: The Survey}

According to steps (3) and (4), a web-based survey among experts was carried out to obtain their judgements. The selection of experts considered the national scale of the research and the multi-perspective of the topic. Consequently, experts are Italian academics, practitioners, and aware e-PMV users. They were identified according to three sources. Academics were selected by Scopus for keywords (i.e., e-PMVs) and country. Thanks to the Google and LinkedIn search engines, practitioners were identified both in research and in their specific skills. Next, a random sampling criterion was followed. Aware e-PMVs users were selected through national associations (i.e., Club Monopattini Italiani and AIIT). A total of 103 experts was selected from January to February 2020.

The survey was developed as a web questionnaire through a free platform. Although several platforms for the survey planning and submission exist (e.g., Survio, Google form, Fyrebox, etc.), many have shortcomings in terms of functionalities, i.e., manage matrices and pairwise comparisons, unlimited program questions, set interfaces, and data export. According to the required functionalities, we adopted the "SondaggioOnline" platform. Indeed, the free-access platform enabled us to build comparisons in pairs, manage a number of questions, and export the data in excel in order to facilitate processing. However, the number of responses was limited in the free version (i.e., 350 responses in one month whereas the two questionnaires required 13 and 432 answers per expert, respectively), so a "personal" license was bought.

The survey was organised into two parts, which represented a wave of data collection. The first part of the survey was carried out between March and April 2020, and experts were required to evaluate each item according to an adjusted version of the Saaty's Semantic Scale [47-49] on a nine-point scale (Table 4). An example of the first part of the survey was 
shown in Figure 2 for the evaluations of components, and the same logic was applied to the evaluation of the related attributes. Questions were formulated to collect data properly for the AHP. The first part was completed by $38.8 \%$ of the panel of experts.

Table 4. The adjusted AHP rating scale adapted from [12].

\begin{tabular}{|c|c|c|}
\hline $\begin{array}{l}\text { Intensity of } \\
\text { Importance }\end{array}$ & Definition & Description \\
\hline 1 & Equal importance & $\begin{array}{c}\text { The two items that are compared are of } \\
\text { equal importance }\end{array}$ \\
\hline 3 & Moderate importance & $\begin{array}{l}\text { Experience and judgment moderately } \\
\text { favour one item over another }\end{array}$ \\
\hline 5 & $\begin{array}{l}\text { Essential or strong } \\
\text { importance }\end{array}$ & $\begin{array}{l}\text { Experience and judgment favour one item } \\
\text { rather than another }\end{array}$ \\
\hline 7 & Very strong importance & $\begin{array}{l}\text { Experience and judgment definitely favour } \\
\text { one item over another }\end{array}$ \\
\hline 9 & Extreme importance & $\begin{array}{c}\text { Experience and judgment definitely favour } \\
\text { one item over another }\end{array}$ \\
\hline $2,4,6,8$ & $\begin{array}{l}\text { Intermediate values } \\
\text { between the two adjacent }\end{array}$ & $\begin{array}{l}\text { In some cases, experience and judgment } \\
\text { could be better explained through } \\
\text { intermediate values }\end{array}$ \\
\hline
\end{tabular}

Would you give more importance to a parameter based on methodological or sustainability component?

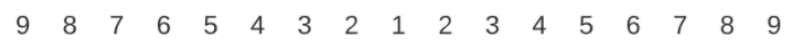

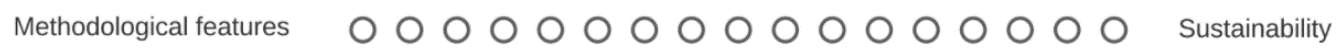

Figure 2. Part 1. Example of the questionnaire for pairwise comparisons of components.

The second part of the survey was carried out in one wave of data collection between March and April 2020. Experts were required to evaluate the long list of parameters correlated to each attribute of each component. The judgment was expressed through a value between 1 (the worst) and 10 (the best). An example of the second part of the survey was shown in Figure 3. The participation rate in the second part was $10.7 \%$ of the panel of experts.

Assign a value from 1 to 10 to evaluate each parameter against each attribute:

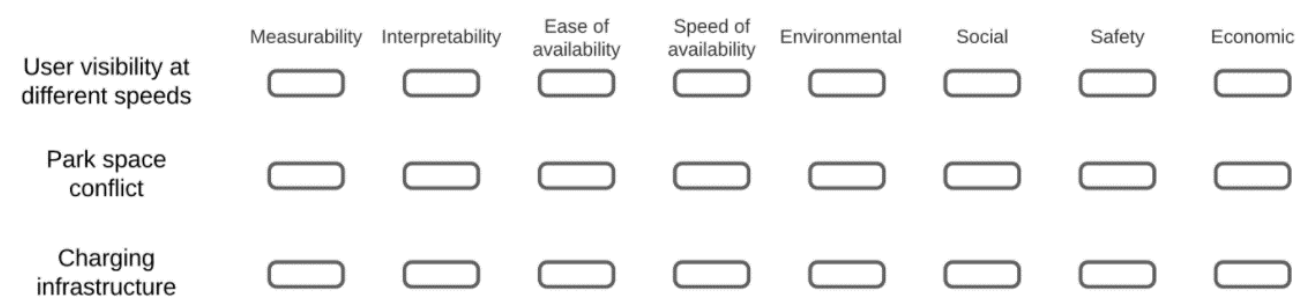

Figure 3. Part 2. Example of the questionnaire for the evaluation of the long list of KSPs.

A summary of the information about participation phases is reported in Table 5. Interestingly, practitioners actively participated in the first part of the survey, unlike the second part of parameters evaluations where academics were most numerous despite the low number. 
Table 5. Expert panel composition and participation rate in the web survey.

\begin{tabular}{cccc}
\hline Experts & Involved & First Part & Second Part \\
\hline Academics & 15 & $8(53.3 \%)$ & $6(40.0 \%)$ \\
Practitioners & 69 & $25(36.2 \%)$ & $4(5.7 \%)$ \\
Users & 19 & $7(36.8 \%)$ & $1(5.2 \%)$ \\
\hline Total & 103 & $40(38.8 \%)$ & $11(10.6 \%)$ \\
\hline
\end{tabular}

\subsection{Data Processing and Reporting: The Ranking of Parameters}

According to Step (5) of the method, the AHP was applied to calculate the weights of components and related attributes, which summarised each expert's preferences. The weights of each item were computed according to Equations (1) and (2), while consistency was evaluated by eqns. from (3) to (5). The weights were reported in an aggregate manner owing to the low number of experts interviewed. A synthesis of overall weights computed by AHP is shown in Table 6. It reports the standard deviation and the coefficient of variation. Table 6 is self-explanatory: the weights show the differences obtained from experts' opinions with respect to the methodological and sustainability components and related attributes, respectively.

Table 6. Overall weight for the three pairwise comparisons of the questionnaire.

\begin{tabular}{cccc}
\hline Components/Attributes & Mean Weight & $\begin{array}{c}\text { Standard } \\
\text { Deviation }\end{array}$ & $\begin{array}{c}\text { Coefficient of } \\
\text { Variation }\end{array}$ \\
\hline Sustainability component & 0.530 & 0.135 & 0.253 \\
\hline Safety & 0.282 & 0.026 & 0.094 \\
Environmental & 0.268 & 0.023 & 0.088 \\
Social & 0.243 & 0.026 & 0.107 \\
Economic & 0.207 & 0.027 & 0.131 \\
\hline Methodological component & 0.470 & 0.135 & 0.288 \\
\hline Easy availability & 0.260 & 0.029 & 0.111 \\
Measurability & 0.250 & 0.030 & 0.103 \\
Speed availability & 0.245 & 0.033 & 0.151 \\
Interpretability & 0.245 & 0.042 & 0.166 \\
\hline
\end{tabular}

As shown in Table 6, experts gave a slightly higher relevance to the sustainability component (0.53) than the methodological one (0.47). Moreover, the quality of results is demonstrated in Table 6 by the low values returned by the coefficient of variation close to zero $(0.253 ; 0.288)$.

On the one hand, no relevant difference was reported in the three attributes of the methodological component because the attributes reported similar weights $(25 \%)$. However, the results of the experts' judgment identified the ease of availability (26\%) of parameters as the most relevant attribute to consider when evaluating the methodological component.

On the other hand, there was a difference in the weight between each attribute of the sustainability component. Practitioners and academics agreed on the primary relevance of the safety $(28.2 \%)$ and environmental $(26.8 \%)$ attributes. This reflects the previous literature results (i.e., Table 1), which are defined as primary categories of safety in terms of crash severity, road safety, conflicts on driving behaviour; meanwhile, the environmental facets include a sustainable modal shift and LCA. The interpretation of the resulting sustainability was very practical. Subsequently, less weight was attributed by experts to social $(24.3 \%)$ and economic $(20.7 \%)$ attributes. These results were partially expected for social instead of economic sustainability, usually very relevant for practitioners and particularly for public administrators.

Once the weights of components and related attributes were obtained, and marks were given to each parameter against each attribute, the SI was computed for each KSP 
by Equations (6) to (12). Next, according to Step (6) of the method, each KSP was ranked in decreasing order. Results are shown in Figure 4. It reports the list of top 15 KSPs that correspond to the first quartile of the rank-ordering distribution of all KSPs. A complete list of rank-ordering is reported in Appendix B.

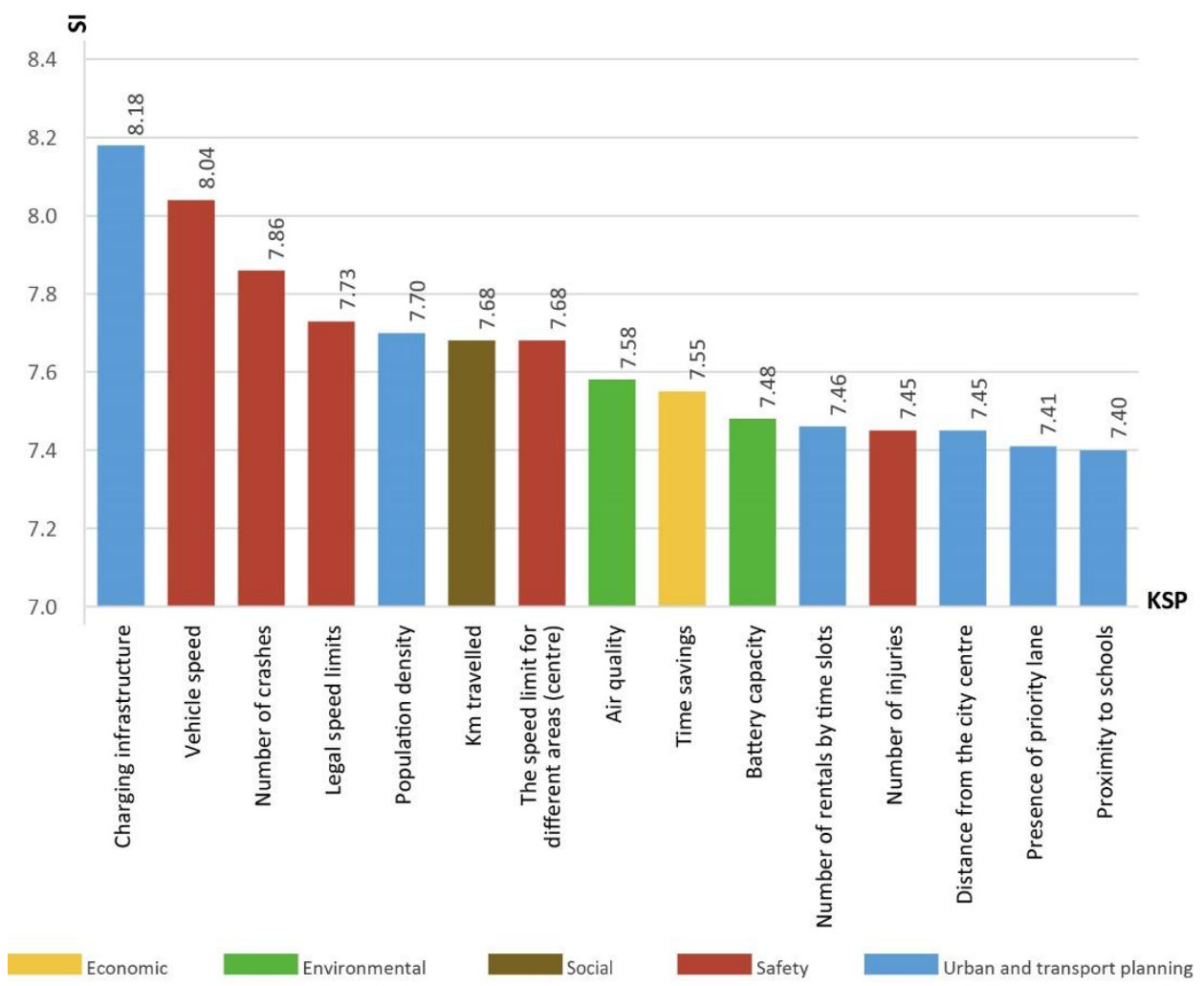

Figure 4. The top KSPs.

\section{Discussions}

This cohesive method represents the first research attempt to identify and select the most promising KSPs regarding e-PMV performance. Consequently, these findings present opportunities and challenges for academics, practitioners, and public administrators: they can be used as a starting point to evaluate and implement existing strategies or address new ones capable of positively impacting the urban transport systems, based on the measurement of KSPs. However, the results obtained according to the three phases described in Section 4 deserve interesting considerations.

First, it is worth noting that the long list of KSPs (Appendix A) represents an original element of this study (phase A). Nevertheless, the construction of the long list of parameters using an indirect method (i.e., literature review) is a starting point for theoretical and applied research.

Second, Table 5 (phase B) provides the summary results of the participation rate in the survey, and it showed very different levels of response among experts in the two parts. There was a response of $53 \%$ of academics and $37 \%$ of practitioners and users in the first part. In the second part, the response rate of non-academics dropped by about $31 \%$ instead of $13 \%$ of academics. This drop can be explained by the different response times required in the two interview parts and which affects the performance of the web surveys. From about $10 \mathrm{~min}$ of the first, the second step of the questionnaire could take up to $60 \mathrm{~min}$. Therefore, the level of participation by type of expert changes according to the time that can be spent on the research.

Third, Figure 4 (phase C) shows that all five key criteria are represented in this list by a different number of parameters. It is worth noting that just one economic parameter is included. This suggests a minor (and unexpected) attention to economic facets typical in 
transport investment. Perhaps, the little amount of money involved to acquire and manage e-PMVs might explain these results. Furthermore, the most promising set of KSPs has high relevance to urban and transport planning and safety. Urban and transport planning parameters are six of fifteen of the categories, and most focused on infrastructure elements such as charging stations, number of rentals per time slot, and the presence of priority lanes for e-PMVs on the road. There were five safety parameters that generally focused on traffic rules for speed and crashes, including the number of crashes and injuries.

Finally, to further investigate the relevance of the main parameters identified from the proposed cohesive method, we evaluated if the 15 top ranked KSPs are considered equally important in the literature. Consequently, we generate a new ranking of 15 top KSPs through a citation score, i.e., the number of occurrences (or repetitions) of a parameter in the literature considered (Table 1). Figure 5 shows the differences between the two different rankings. Specifically, the literature mainly utilised environmental parameters, unlike the most promising parameters of Urban and transport planning and safety retrieved from the cohesive method. Moreover, commonalities were also observed among the top15 KSP lists: population density and distance from the city centre (Urban and transport planning), air quality (Environmental), time savings (Economic), $\mathrm{km}$ travelled (Social), and the number of injuries (Safety). However, the previous studies (see Table 1) included an average of 1-2 shared top KSPs, demonstrating the originality of the results obtained in this study. The partial exception is the study of Bai \& Jiao [20], which have identified six of fifteen top sub-parameters belonging mainly to the key criteria of Urban and Transport planning. Nevertheless, this difference might be observed because many studies start from parameters already in use in current research. In contrast, the proposed method is an objective alternative that involves other subjects who operate with different skills than academics.

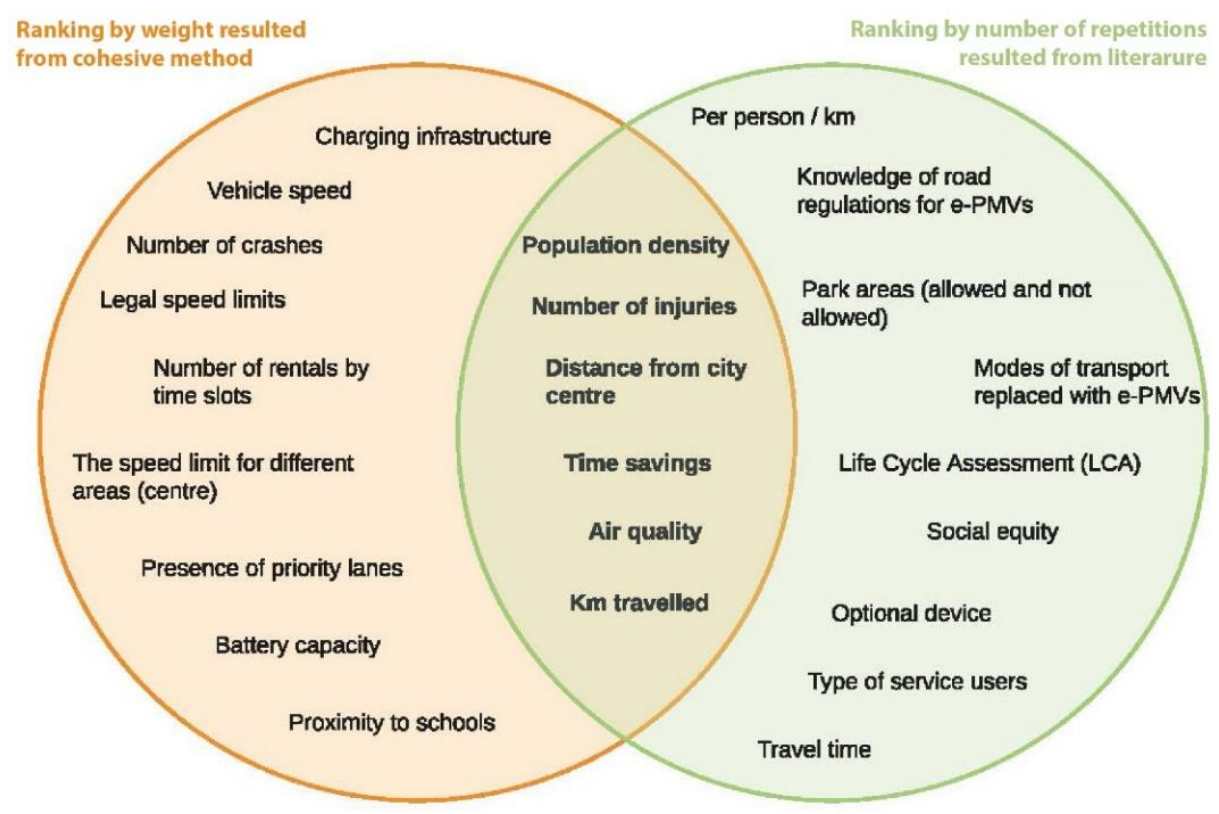

Figure 5. Comparison between the top 15 KSPs provided by 2 alternative methods.

\section{Conclusions}

Owing to the recent invasion of electric-powered personal mobility vehicles (e-PMVs) in many cities worldwide, understanding how to evaluate and monitor their performance is crucial. Therefore, it is essential to identify key sustainable parameters (KSPs) to inform on the excellences and criticalities of e-PMVs. Although studies on e-PMVs are constantly growing, and this field of study is still experimental, previous research has focused largely on models and methods to measure and manage some KSPs. Conversely, it did not investigate objective methods for identifying and selecting the top KSPs. 
To address these gaps, this study contributed to the growing literature on e-PMVs in a threefold manner:

- Identification of a long (and to-date mostly complete) list of KSPs organised into key criteria, parameters and sub-parameters, which affect the performance of e-PMVs.

- Proposal of a new cohesive approach that identified top KSPs from a long list and pointed out the most promising. More precisely, this approach applied a participatory approach and an objective method of weighting and ranking each KSP. The former approach used data collected by an Italian web survey involving academics, practitioners, and aware e-PMV users. The latter approach applied both an AHP, which processed data on the relevance of components and related attributes and a method that computed a score for each KSP. Hence, subjective data (i.e., judgments from experts) are managed to achieve objective conclusions (i.e., the score of each KSP).

- Comparison of outcomes obtained the cohesive approach and by the number of occurrences of each parameter gathered from the literature. A set of six common KSPs was isolated.

- The relevant implications of this study are:

- The identification of the top KSPs may help stakeholders collect e-PMV data in detail and for benchmark purposes.

- The high degree of applicability of the cohesive approach is not strictly linked to the KSPs of e-PMVs but can be generalised for other transportation modes.

- The opportunity to assess e-PMVs among cities according to a common set of KSPs.

To the best of the authors' knowledge, this is the first study that provided a set of KSPs to monitor the performances of e-PMVs according to an objective method.

To conclude, this study presents some shortcomings that raise issues for future research agendas.

First, the long list of KSPs was collected from an international literature review, but the selection of experts is national (Italian). Therefore, the study has a national viewpoint and is small in scale compared to the large number of cities characterised by the use of e-PMVs. Consequently, the study has not considered the possible tradeoff between the specificity of the local and general conditions or the comparability of the selected parameters. However, this limitation could influence the overall results and not the methodology, which is quite generalisable and driven by specific and well-recognised literature reviews. Indeed, the methodology presented here is flexible and applicable to any urban context. The panel of experts considered is decisive, as it is reasonable to think that each expert might provide an assessment that implicitly includes the country in which it operates. For instance, in Italy, where e-PMVs are an emerging transport mode, the most promising KSP obtained by the cohesive method is charging infrastructure; conversely, in countries where this transport mode is consolidated, it could have a different parameter ranking. Moreover, the heterogeneity of countries in their level of development may affect the input data of some parameters. For instance, the setting of a level of service of a spatial parameter (e.g., distance from the city centre) may change: developed countries might adopt a level of service stricter than the developing ones (e.g., $400 \mathrm{~m}$ vs. $800 \mathrm{~m}$ ). However, these differences do not impede measuring the same KSP, even if the benchmark may be biased. Consequently, the long list constitutes an initial milestone, and future research should improve it through interviews with experts from many countries to effectively verify if and how local conditions could affect the choice of KSPs.

Second, the lower data of participation rate in the second part of the survey showed a shortcoming of the method: the outcome mark of each KSP against each attribute consists of a very large number of judgments (i.e., 432 values), which often frighten the expert. Indeed, it could represent an impediment to reaching a more shared evaluation. Despite the participation rate achieved from this study not being too different from web-based surveys [59], future perspectives may either broaden the sample of experts or carry out a Monte Carlo simulation on existing (and few) data. The application of a stochastic 
model could reduce or eliminate the bias of coverage of the small sample of experts and, consequently, their judgments [60].

Author Contributions: The authors confirm contribution to the paper as follow: study conception all; methodology, B.B., E.C., R.C.; formal analysis, M.C, E.C., R.C.; writing-original draft preparation, E.C., R.C., S.B., M.C.; writing-review and editing, B.B., S.B., M.C.; supervision, B.B., G.M.; funding acquisition, B.B., G.M. All authors have read and agreed to the published version of the manuscript.

Funding: This research was partially funded by the University of Brescia, grant number "CUP: E81B19000840007" and POR FESR Lombardia 2014-2020 (project: MoSoRe).

Institutional Review Board Statement: Not applicable.

Informed Consent Statement: Not applicable.

Data Availability Statement: Some or all data, models, or code generated or used during the study are proprietary or confidential in nature and may only be provided with restrictions.

Acknowledgments: The authors are grateful to Michela Bonera for her constructive comments on an earlier draft of the manuscript.

Conflicts of Interest: The authors declare no conflict of interest.

\section{Appendix A}

Table A1. Classification of parameters.

\begin{tabular}{|c|c|c|c|}
\hline Key Criteria & Parameters & Sub-Parameters & Sub-Sub-Parameters \\
\hline \multirow{2}{*}{ Economic } & \multirow[t]{2}{*}{ User costs } & Time savings & - \\
\hline & & Cost of travel & - \\
\hline \multirow{15}{*}{ Environmental } & \multirow[t]{4}{*}{ Energy saving } & Battery capacity & - \\
\hline & & Urban transport choices & - \\
\hline & & Consumption of energy use & - \\
\hline & & Use of renewable energy & Recharging \\
\hline & \multirow[t]{4}{*}{$\mathrm{CO} 2$ release } & For transport from the manufacturers & 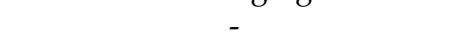 \\
\hline & & For materials and production processes & - \\
\hline & & Charging stations & - \\
\hline & & Per person/km & - \\
\hline & \multirow[t]{7}{*}{ Other emissions } & Air quality & - \\
\hline & & Interchangeable battery use & - \\
\hline & & Life cycle assessment (LCA) & - \\
\hline & & e-PMV daily management & - \\
\hline & & Fuel consumption types & - \\
\hline & & The durability of functional safety systems & Personal and System equipment \\
\hline & & Noise pollution & - \\
\hline \multirow{11}{*}{ Safety } & \multirow{7}{*}{ Perception of safety } & Number of injuries & Orthopaedic \\
\hline & & & Polytrauma \\
\hline & & & Head lesions \\
\hline & & & Musculoskeletal system \\
\hline & & Number of crashes & - \\
\hline & & By pedestrians & - \\
\hline & & By e-PMVs users & - \\
\hline & \multirow[t]{4}{*}{ Vehicle features } & Optional device & Acoustic signaling \\
\hline & & & $\begin{array}{l}\text { Warning lights and indicators of } \\
\text { rear visibility }\end{array}$ \\
\hline & & & Steering capacity \\
\hline & & & Anti-tampering measures \\
\hline
\end{tabular}


Table A1. Cont.

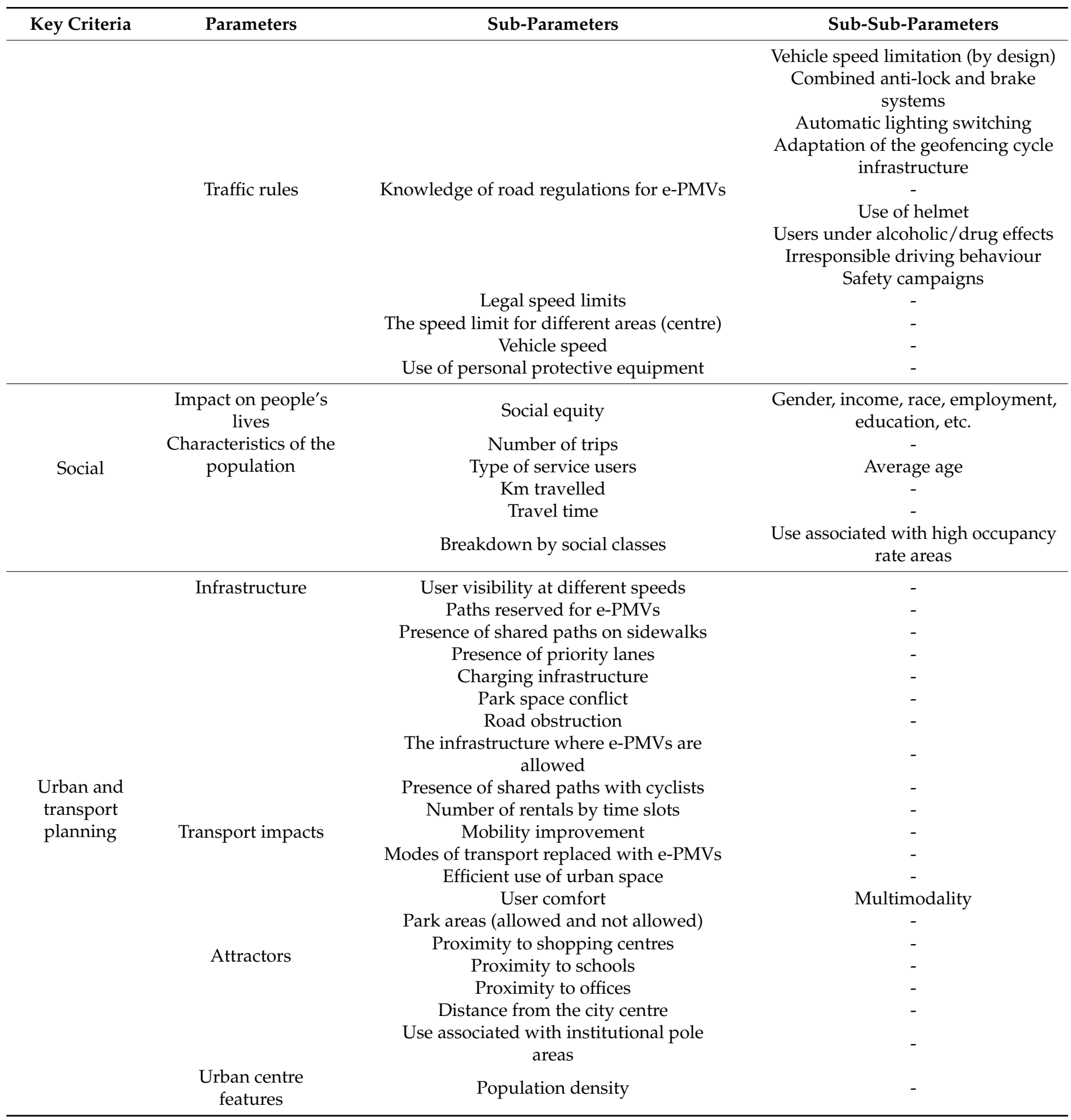




\section{Appendix B}

Table A2. The overall ranking of sub-parameters.

\begin{tabular}{|c|c|c|c|c|}
\hline N. & Key Criteria & Parameters & Sub-Parameters Classification & SI \\
\hline 1 & Urban and transport planning & Infrastructure & Charging infrastructure & 8.18 \\
\hline 2 & Safety & Traffic rules & Vehicle speed & 8.04 \\
\hline 3 & Safety & Crashes & Number of crashes & 7.86 \\
\hline 4 & Safety & Traffic rules & Legal speed limits & 7.73 \\
\hline 5 & Urban and transport planning & Urban centre features & Population density & 7.70 \\
\hline 6 & Social & $\begin{array}{l}\text { Characteristics of the } \\
\text { population }\end{array}$ & Km travelled & 7.68 \\
\hline 7 & Safety & Traffic rules & $\begin{array}{l}\text { The speed limit for different areas } \\
\text { (centre) }\end{array}$ & 7.68 \\
\hline 8 & Environmental & Other emissions & Air quality & 7.58 \\
\hline 9 & Economic & User cost & Time savings & 7.55 \\
\hline 10 & Environmental & Energy saving & Battery capacity & 7.48 \\
\hline 11 & Urban and transport planning & Infrastructure & Number of rentals by time slots & 7.46 \\
\hline 12 & Safety & Crashes & Number of injuries & 7.45 \\
\hline 13 & Urban and transport planning & Attractors & Distance from the city centre & 7.45 \\
\hline 14 & Urban and transport planning & Infrastructure & Presence of priority lane & 7.41 \\
\hline 15 & Urban and transport planning & Attractors & Proximity to schools & 7.40 \\
\hline 16 & Urban and transport planning & Infrastructure & $\begin{array}{c}\text { The infrastructure where e-PMVs } \\
\text { are allowed }\end{array}$ & 7.33 \\
\hline 17 & Urban and transport planning & Attractors & Proximity to shopping centres & 7.29 \\
\hline 18 & Environmental & Energy saving & Use of renewable energy & 7.25 \\
\hline 19 & Urban and transport planning & Infrastructure & Paths reserved for e-PMVs & 7.23 \\
\hline 20 & Urban and transport planning & Infrastructure & Road obstruction & 7.23 \\
\hline 21 & Urban and transport planning & Transport impacts & $\begin{array}{c}\text { Modes of transport replaced with } \\
\text { e-PMVs }\end{array}$ & 7.22 \\
\hline 22 & Social & $\begin{array}{l}\text { Characteristics of the } \\
\text { population }\end{array}$ & Number of trips & 7.18 \\
\hline 23 & Environmental & Other emissions & Life cycle assessment (LCA) & 7.10 \\
\hline 24 & Social & $\begin{array}{l}\text { Characteristics of the } \\
\text { population }\end{array}$ & Travel time & 7.02 \\
\hline 25 & Environmental & Other emissions & Noise pollution & 7.01 \\
\hline 26 & Environmental & $\mathrm{CO} 2$ release & Per person $/ \mathrm{km}$ & 6.99 \\
\hline 27 & Urban and transport planning & Infrastructure & $\begin{array}{c}\text { Presence of shared paths with } \\
\text { cyclists }\end{array}$ & 6.97 \\
\hline 28 & Urban and transport planning & Infrastructure & $\begin{array}{l}\text { Presence of shared paths on } \\
\text { sidewalks }\end{array}$ & 6.96 \\
\hline 29 & Urban and transport planning & Transport impacts & Efficient use of urban space & 6.94 \\
\hline 30 & Urban and transport planning & Attractors & Proximity to offices & 6.94 \\
\hline 31 & Safety & Traffic rules & $\begin{array}{c}\text { Use of personal protective } \\
\text { equipment }\end{array}$ & 6.92 \\
\hline 32 & Urban and transport planning & Attractors & $\begin{array}{l}\text { Park areas (allowed and not } \\
\text { allowed) }\end{array}$ & 6.91 \\
\hline 33 & Environmental & Other emissions & Interchangeable battery use & 6.88 \\
\hline 34 & Environmental & Other emissions & Fuel consumption types & 6.87 \\
\hline 35 & Environmental & Energy saving & Consumption of energy use & 6.85 \\
\hline 36 & Environmental & Other emissions & $\begin{array}{l}\text { The durability of functional safety } \\
\text { systems }\end{array}$ & 6.83 \\
\hline 37 & Safety & Traffic rules & $\begin{array}{c}\text { Knowledge of road regulations for } \\
\text { e-PMVs }\end{array}$ & 6.79 \\
\hline 38 & Environmental & Energy saving & Urban transport choices & 6.76 \\
\hline 39 & Urban and transport planning & Infrastructure & Park space conflict & 6.70 \\
\hline 40 & Urban and transport planning & Transport impacts & Mobility improvement & 6.68 \\
\hline 41 & Safety & Vehicle features & Optional device & 6.66 \\
\hline 42 & Economic & User costs & Cost of travel & 6.64 \\
\hline
\end{tabular}


Table A2. Cont.

\begin{tabular}{|c|c|c|c|c|}
\hline N. & Key Criteria & Parameters & Sub-Parameters Classification & SI \\
\hline 43 & Environmental & $\mathrm{CO} 2$ release & Materials and production processes & 6.64 \\
\hline 44 & Social & Impact on people's lives & Social equity & 6.64 \\
\hline 45 & Environmental & Other emissions & e-PMV daily management & 6.58 \\
\hline 46 & Urban and transport planning & Transport impacts & User comfort & 6.56 \\
\hline 47 & Social & $\begin{array}{c}\text { Characteristics of the } \\
\text { population }\end{array}$ & Type of service users & 6.44 \\
\hline 48 & Environmental & $\mathrm{CO} 2$ release & Charging stations & 6.36 \\
\hline 49 & Safety & Perception of safety & By pedestrians & 6.35 \\
\hline 50 & Safety & Perception of safety & By e-PMVs users & 6.33 \\
\hline 51 & Environmental & $\mathrm{CO} 2$ release & $\begin{array}{l}\text { For transport from the } \\
\text { manufacturers }\end{array}$ & 6.21 \\
\hline 52 & Urban and transport planning & Infrastructure & User visibility at different speeds & 6.15 \\
\hline 53 & Social & $\begin{array}{c}\text { Characteristics of the } \\
\text { population }\end{array}$ & Breakdown by social classes & 5.74 \\
\hline 54 & Urban and transport planning & Attractors & $\begin{array}{l}\text { Use associated with institutional } \\
\text { pole areas }\end{array}$ & 5.40 \\
\hline
\end{tabular}

\section{References}

1. Luo, J.; Boriboonsomins, K.; Barth, M. Consideration of Exposure to Traffic-Related Air Pollution in Bicycle Route Planning. J. Transp. Health 2020, 16, 100792. [CrossRef]

2. Luo, X.; Qiu, R. Electric Vehicle Charging Station Location towards Sustainable Cities. Int. J. Environ. Res. Public Health 2020, 17, 2785. [CrossRef] [PubMed]

3. Chang, A.Y.; Miranda-Moreno, L.; Clewlow, R.; Sun, L. Trend or Fad? Deciphering the Enablers of Micromobility in the U.S.; SAE International: Warrendale, PA, USA, 2019.

4. Severengiz, S.; Finke, S.; Schelte, N.; Wendt, N. Life Cycle Assessment on the Mobility Service E-Scooter Sharing. In Proceedings of the 2020 IEEE European Technology and Engineering Management Summit (E-TEMS), Dortmund, Germany, 5-7 March 2020; IEEE: Dortmund, Germany, 2020; pp. 1-6.

5. Hollingsworth, J.; Copeland, B.; Johnson, J.X. Are E-Scooters Polluters? The Environmental Impacts of Shared Dockless Electric Scooters. Environ. Res. Lett. 2019, 14, 084031. [CrossRef]

6. De Bortoli, A.; Christoforou, Z. Consequential LCA for Territorial and Multimodal Transportation Policies: Method and Application to the Free-Floating e-Scooter Disruption in Paris. J. Clean. Prod. 2020, 273, 122898. [CrossRef]

7. Moreau, H.; de Jamblinne de Meux, L.; Zeller, V.; D'Ans, P.; Ruwet, C.; Achten, W.M.J. Dockless E-Scooter: A Green Solution for Mobility? Comparative Case Study between Dockless E-Scooters, Displaced Transport, and Personal E-Scooters. Sustainability 2020, 12, 1803. [CrossRef]

8. O'Hern, S.; Estgfaeller, N. A Scientometric Review of Powered Micromobility. Sustainability 2020, 12, 9505. [CrossRef]

9. Boglietti, S.; Barabino, B.; Maternini, G. Survey on e-powered micro personal mobility vehicles: Exploring current issues towards future developments. Sustainability 2021, 13, 3692. [CrossRef]

10. Şengül, B.; Mostofi, H. Impacts of E-Micromobility on the Sustainability of Urban Transportation-A Systematic Review. Appl. Sci. 2021, 11, 5851. [CrossRef]

11. Castillo, H.; Pitfield, D.E. ELASTIC-A methodological framework for indentifying and selecting sustainable transport indicators. Transp. Res. Part D Transp. Environ. 2010, 15, 179-188. [CrossRef]

12. Barabino, B.; Cabras, N.A.; Conversano, C.; Olivo, A. An Integrated Approach to Select Key Quality Indicators in Transit Services. Soc. Indic. Res. 2020, 149, 1045-1080. Available online: https://link.springer.com/article/10.1007\%2Fs11205-020-02284-0 (accessed on 16 December 2020). [CrossRef]

13. Abduljabbar, R.L.; Liyanage, S.; Dia, H. The role of micro-mobility in shaping sustainable cities: A systematic literature review. Transp. Res. Part D Transp. Environ. 2021, 92, 102734. [CrossRef]

14. Smith, S.C.; Schwieterman, J.P. E-Scooter Scenarios: Evaluating the Potential Mobility Benefits of Shared Dockless Scooters in Chicago; Chaddick Institute Policy: Technical Report; Chaddick Institute Policy Series: Chicago, IL, USA, 2018.

15. Hwang, J.J. Sustainable transport strategy for promoting zero-emission electric scooters in Taiwan. Renew. Sustain. Energy Rev. 2010, 14, 1390-1399. [CrossRef]

16. Badeau, A.; Charman, C.; Newman, M.; Steenblik, J.; Carlson, M.; Mardsen, T. Emergency department visits for electric scooter-related injuries after introduction of an urban rental program. Am. J. Emerg. Med. 2019, 37, 1531-1533. [CrossRef] [PubMed]

17. Clewlow, R.R. The Micro-Mobility Revolution: The Introduction and Adoption of Electric Scooters in the United States; A Populus Research Report; Transportation Research Board 98th Annual Meeting: Washington, DC, USA, 2018.

18. Gossling, S. Why cities need to take road space from cars-And how this could be done. J. Urban Des. 2020, 25, 443-448. [CrossRef] 
19. Bai, S.; Jiao, J. Dockless E-scooter usage patterns and urban built Environments: A comparison study of Austin, TX, and Minneapolis, MN. Travel Behav. Soc. 2020, 20, 264-272. [CrossRef]

20. Cao, Z.; Zhang, X.; Chua, K.; Yu, H.; Zhao, J. E-scooter sharing to serve short-distance transit trips: A Singapore case. Transp. Res. Part A Policy Pract. 2021, 147, 177-196. [CrossRef]

21. Scarpinella, M.S. Micromobilità e Adeguamento Infrastrutturale: Continua la Sperimentazione in Italia. 2020. Available online: https: / www.qualenergia.it/articoli/micromobilita-e-adeguamento-infrastrutturale-continua-la-sperimentazione-initalia/ (accessed on 16 December 2020).

22. Reck, D.J.; Haitao, H.; Guidon, S.; Axhausen, K.W. Explaining shared micromobility usage, competition and mode choice by modelling empirical data from Zurich, Switzerland. Transp. Res. Part C Emerg. Technol. 2021, 124, 102947. [CrossRef]

23. Hosseinzadeh, A.; Algomaiah, M.; Kluger, R.; Li, Z. Spatial analysis of shared e-scooter trips. J. Transp. Geogr. 2021, 92, 103016. [CrossRef]

24. James, O.; Swiderski, J.; Hicks, J.; Teoman, D.; Buehler, R. Pedestrians and E-Scooters: An Initial Look at E-Scooter Parking and Perceptions by Riders and Non-Riders. Sustainability 2019, 11, 5591. [CrossRef]

25. Schellong, D.; Sadek, P.; Schaetzberger, C.; Barrack, T. The Promise and Pitfalls of E-Scooter Sharing; Boston Consulting Group: Boston, MA, USA, 2019.

26. Gitelman, V.; Korchatov, A.; Hakkert, S. Alternative transport means in city centers: Exploring the levels of use, typical behaviours and risk factors. Eur. Transp. Trasp. Eur. 2020, 77, 1-11. Available online: http://www.istiee.unict.it/sites/default/files/files/2 3_ET_30.pdf (accessed on 30 December 2020). [CrossRef]

27. Caspi, O.; Smart, M.; Noland, R. Spatial associations of dockless shared e-scooter usage. Transp. Res. Part D Transp. Environ. 2020, 86, 102396. [CrossRef]

28. Møller, T.H.; Simlett, J.; Mugnier, E. Micromobility: Moving Cities into a Sustainable Future; EY: London, UK, 2019.

29. Alessio, F. Rain Shield System; Università degli Studi di Camerino. Technical Report: Camerino, Italy, 2019.

30. Christoforou, Z.; de Bortoli, A.; Gioldasis, C.; Seidowsky, R. Who is using e-scooters and how? Evidence from Paris. Transp. Res. Part D Transp. Environ. 2021, 92, 102708. [CrossRef]

31. Hawa, L.; Cui, B.; Sun, L.; El-Geneidy, A. Scoot over: Determinants of shared electric scooter presence in Washington D.C. Case Stud. Transp. Policy 2021, 9, 418-430. [CrossRef]

32. International Transport Forum. Safe Micromobility; OECD: Paris, France, 2020; Available online: https://www.itf-oecd.org/sites/ default/files/docs/safe-micromobility_1.pdf (accessed on 30 December 2020).

33. Kopplin, C.S.; Brand, B.M.; Reichenberger, Y. Consumer acceptance of shared e-scooters for urban and short-distance mobility. Transp. Res. Part D Transp. Environ. 2021, 91, 102680. [CrossRef]

34. Nocerino, R.; Colorni, A.; Lia, F.; Luè, A. E-bikes and E-scooters for Smart Logistics: Environmental and Economic Sustainability in Pro-E-bike Italian Pilots. Transp. Res. Procedia 2016, 14, 2362-2371. [CrossRef]

35. Piazza, G.; Bracco, S.; Delfino, F.; Siri, S. Optimal design of electric mobility services for a Local Energy Community. Sustain. Energy Grids Netw. 2021, 26, 100440. [CrossRef]

36. Siow, M.; Lavoie-Gagne, O.; Politzer, C.; Mitchell, B.; Harkin, W.; Flores, A.; Kent, W. Electric scooter orthopaedic injury demographics at an urban level I trauma center. J. Orthop. Trauma 2020, 34, 424-429. [CrossRef] [PubMed]

37. Brundtland Commission. Our Common Future; World Commission for the Environment and Development: Stockholm, Sweden, 1987.

38. Keirstead, J.; Leach, M. Bridging the gaps between theory and practice: A service niche approach to urban sustainability indicators. Sustain. Dev. 2008, 16, 329-340. [CrossRef]

39. Zelany, M. A concept of compromise solutions and the method of the displaced ideal. Comput. Oper. Res. 1974, 1, 479-496. [CrossRef]

40. Hens, L.; De Wit, J. The development of indicators and core indicators for sustainable development: A state of the art review. Int. J. Sustain. Dev. 2003, 6, 436-459. [CrossRef]

41. CEN/TC 320. Transportation-Logistics and Services, European Standard EN 15140: Public Passenger Transport-Basic Requirements and Recommendation for Systems That Measure Delivered Service Quality; Technical Report; European Committee for Standardization: Brussels, Belgium, 2006.

42. Wang, T.C.; Lee, H.D. Developing a fuzzy TOPSIS approach based on subjective weights and objective weights. Experts Syst. Appl. 2009, 36, 8980-8985. [CrossRef]

43. Pohekar, S.D.; Ramachandran, M. Application of multi-criteria decision making to sustainable energy planning-A review. Renew. Sustain. Energy Rev. 2004, 8, 365-381. [CrossRef]

44. Yedla, S.; Shrestha, R.M. Multi-criteria approach for the selection of alternative options for environmentally sustainable transport system in Delhi. Transp. Res. Part A Pol. Pract. 2003, 37, 717-729. [CrossRef]

45. Lin, G.; Wang, S.; Lin, C.; Bu, L.; Xu, H. Evaluating Performance of Public Transport Networks by Using Public Transport Criteria Matrix Analytic Hierarchy Process Models-Case Study of Stonnington, Bayswater, and Cockburn Public Transport Network. Sustainability 2021, 13, 6949. [CrossRef]

46. Jain, S.; Aggarwal, P.; Kumar, P.; Singhal, S.; Prateek, S. Identifying public preferences using multi-criteria decision making for assessing the shift of urban commuters from private to public transport: A case study of Delhi. Transp. Res. Part F Traffic Psychol. Behav. 2014, 24, 60-70. [CrossRef] 
47. Saaty, T.L. A scaling method for priorities in hierarchical structures. J. Math. Psychol. 1977, 15, 234-281. [CrossRef]

48. Saaty, T.L. The analytic hierarchy process-What it is and how it is used. Math. Model. 1987, 9, 161-176. [CrossRef]

49. Saaty, T.L. Highlights and critical points in the theory and application of the analytic hierarchy process. Eur. J. Oper. Res. 1994, 74, 426-447. [CrossRef]

50. Wind, Y.; Saaty, T.L. Marketing applications of analytic hierarchy process. Manag. Sci. 1980, 26, 641-658. [CrossRef]

51. Figueira, J.; Greco, S.; Ehrgott, M. Multiple Criteria Decision Analysis: State of the Art Surveys. In International Series in Operations Research and Management Science; Springer: Boston, MA, USA, 2005; Volume 78.

52. Forman, E.H.; Gass, S.I. The analytical hierarchy process-an exposition. Oper. Res. 2001, 49, 469-487. [CrossRef]

53. Millet, I.; Wedley, W.C. Modelling Risk and Uncertainty with the Analytic Hierarchy Process. J. Multi-Criteria Decis. Anal. 2002, 11, 97-107. [CrossRef]

54. Macharis, C.; Springael, J.; De Brucker, K.; Verbeke, A. Promethee and AHP: The design of operational synergies in multicriteria analysis. Strengthening Promethee with ideas of AHP. Eur. J. Oper. Res. 2004, 153, 307-317. [CrossRef]

55. Oguztimur, S. Why fuzzy analytic hierarchy process approach for transport problems? In Proceedings of the 51st Congress of the European Regional Science Association, Barcelona, Spain, 30 August-3 September 2011.

56. Saaty, T.L.; Peniwati, K. Group Decision Making: Drawing out and Reconciling Differences; RWS Publications: Pittsburgh, Pennsylvania, 2008.

57. Too, L.; Earl, G. Public transport service quality and sustainable development: A community stakeholder perspective. Sustain Dev. 2010, 18, 51-61. [CrossRef]

58. Aladwani, A.M.; Palvia, P.C. Developing and validating an instrument for measuring user-perceived web quality. Inf. Manag. 2002, 39, 467-476. [CrossRef]

59. Sivo, S.A.; Saunders, C.; Chang, Q.; Jiang, J.J. How low should you go? Low response rates and the validity of inference in IS questionnaire research. J. Assoc. Inf. Syst. 2006, 7, 351-414. [CrossRef]

60. Dever, J.A.; Rafferty, A.; Valliant, R. Internet surveys: Can statistical adjustments eliminate coverage bias? Surv. Res. Methods 2008, 2, 47-62. 